Original article

\title{
Perceptions and practices of COVID-19 protective measures among the general public of North India
}

\author{
Tuhina Rastogi ${ }^{\text {a }}$, Shally Awasthi ${ }^{\text {a, }}$, Ranjan Khare ${ }^{\mathrm{a}, 1}$, Mahesh Prasad ${ }^{\mathrm{a}, 1}$, Gulshan Sami ${ }^{\mathrm{a}, 1}$, \\ Vijay Kumar Verma ${ }^{\text {a, } 1}$ \\ a Department of Pediatrics, King George's Medical University, Lucknow, Uttar Pradesh, 226003, India
}

\section{A R T I C L E I N F O}

\section{Keywords:}

COVID-19

Qualitative

India

Protective measures

Pandemic

Public

\begin{abstract}
A B S T R A C T
Background: India has a high COVID-19 burden. The Indian government responded to the pandemic by mandating its population to adhere to certain Protective Measures (PMs). Compliance to these PMs depends on their acceptability and adaptability among the general public.

Aims: To explore the perceptions and practices of COVID-19 related PMs among the general public of North India. Methods: Qualitative study in four administrative districts (Lucknow, Etawah, Patna and Darbhanga) of North India. Two urban and two rural districts were purposefully selected. Audio in-depth interviews (IDIs) were conducted with healthy caregivers of children (2-59 months). Data was managed using Atlast Ti and analyzed using conventional content analysis.

Results: From July-Sep 2020, 60 IDIs were conducted; 36.6\% (22/60) were females and 26.6\% (16/60) had below primary education. Respondents concurred that most people in their society flouted the recommended PMs. The reasons for poor/non-compliance with PMs were: perceived poor susceptibility to illness, perceived less severity of COVID-19 and low perceived benefits of complying with the PMs. Respondents opined that COVID-19 is less prevalent in rural areas and among the educated population. Most respondents were aware of the recommended PMs and opined that these must be followed, however subjective norms, social norms and behavioral intentions negatively impacted compliance.

Conclusions: Since there was poor community perception of susceptibility to COVID-19 as well as poor perceived severity, the community did not understand the benefits of adhering to the recommended PMs. Therefore, future health communication strategies must take these into account to increase the possibility of success.
\end{abstract}

\section{Introduction}

Coronavirus disease 2019 (COVID-19), caused by severe acute respiratory syndrome coronavirus 2 , has spread rapidly across the globe, leading the World Health Organization to declare it as a pandemic. ${ }^{1}$ The outbreak has resulted in 113.47 million confirmed cases and 2.52 million deaths globally till February 2, 021. ${ }^{2}$ COVID-19 transmits rapidly through human-to-human transmission either by direct contact or via droplets. ${ }^{3}$ In order to reduce the risk of transmission and secondary infections, it is imperative that measures be taken to limit human-to-human transmission, prevent events that amplify such transmissions and promote WHO- recommended infection control interventions. $^{4}$ Till the time vaccines are widely accepted, non-pharmacological protective measures (PMs) for COVID-19 is the most important intervention strategy to contain the spread of this disease. $^{5}$

India was one of the worst-hit Covid-19 affected countries in the world with total COVID-19 positive cases crossing 11.09 million and mortality over 157,051 till February $2021 .^{6}$ The Government of India (GoI) responded to the pandemic by mandating their population to adhere to certain generic PMs. These PMs are either 'preventive' behaviors like keeping social distancing, washing hands frequently and thoroughly, following respiratory etiquettes, not spitting in public and mandatorily wearing face covers/face-masks when in public or 'avoidant' behaviors like avoiding crowded places, avoiding using public transport and following quarantine rules. ${ }^{7-9}$

Since COVID-19 pandemic requires large-scale behavior change, it is imperative to provide social and behavioral evidence that helps to

\footnotetext{
* Corresponding author.

E-mail address: shally07@gmail.com (S. Awasthi).

1 These authors contributed equally to this work.
} 
manage and mitigate this pandemic. The current study was therefore designed to explore the perceptions and practices related to compliance to COVID-19 related PMs among the general public of North India. The study was conducted from July-September 2020; at the time when the GoI had begun easing restrictions ${ }^{10}$ and there were government guidelines for the same. ${ }^{6}$ In this phase of unlocking, the compliance of general public towards COVID-19 related PMs depended more on willingness and understanding of the people to follow it.

\subsection{Theoretical model}

Our study uses the Health Belief Model (HBM) as a theoretical basis. ${ }^{11-13}$ Four key constructs of HBM were used: perceived susceptibility, perceived severity, perceived benefits and perceived barriers. 'Perceived susceptibility', suggests that the more an individual perceives the risk of getting infected with a disease, the more likely s/he will change behavior to minimize the risk. ${ }^{13}$ 'Perceived severity' includes evaluation of the serious consequences of getting infected, based on his/her own knowledge or belief. ${ }^{13}$ 'Perceived benefit' suggests that the individuals evaluate the value and usefulness of adopting new behaviors in regard to minimizing the risk of an illness. The fourth dimension, 'perceived barrier', proposes that individuals evaluate the challenges or barriers they might face when they adopt a new behavior to prevent any illness. ${ }^{11}$ Our study postulates that individuals follow or not follow the recommended PMs for COVID-19 on the basis of beliefs related to the above four constructs.

\section{Methods}

\subsection{Study design and setting}

This was a qualitative study conducted in four administrative districts (Lucknow, Etawah, Patna and Darbhanga) in two states of North India. Lucknow and Patna are predominantly urban while Darbhanga and Etawah are rural. ${ }^{14,15}$ Literacy of the population in Lucknow (77.3\%) and Etawah (78.4\%) is slightly higher while that of Patna (70.7\%) and Darbhanga (68.3\%) is lower than the national average of $73 \% .{ }^{14,15}$ All four study districts also had COVID-19 confirmed active cases at the time of conduction of the study. ${ }^{6}$

\subsection{Study participants}

Participants in this study were healthy caregivers whose children (2-59 months) were enrolled for pneumonia in 2019 in a tertiary care hospital as part of ongoing study. Selection of tertiary care hospitals was purposive, based on high patient load. Caregivers of children in eligible age-group were approached for participation.

Inclusion criteria for selecting prospective respondents was (i) child enrolled in selected hospital for pneumonia but presently discharged (ii) availability of telephone/mobile with the caregiver and (iii) consent to participate in the study. Both male and female respondents were selected. Respondents were also purposefully selected from two education groups (i) Below Primary Education Group: Respondents with $\leq 5$ years of schooling and (ii) Above Primary Education Group: Respondents with $>5$ years of schooling. This ensured variability and heterogeneity in the sample. In our study, respondents were from two different Indian states with different dialects. Hence, those respondents who had difficulty in understanding our dialect were excluded. All participants provided informed consent prior to participation in the study. Interviews were audio-recorded after obtaining permission.

\subsection{Data collection and interviewing}

Researchers used telephonic In-depth interviews (IDI) to collect qualitative data. Since the study was conducted during the COVID-19 pandemic, instead of face-to-face IDIs, 'socially distant' measure of telephonic IDI was adopted. This was done to comply with the public health mandate of the government, as the pandemic restricted our ability to approach respondents' in-person. ${ }^{16}$ Data was collected by four male researchers who were postgraduates and had training and prior experience to conduct qualitative research.

Researchers screened the prospective eligible respondents and approached them for participation through telephone. They were then invited for participation at a date and time convenient to them. The consent form was sent to the prospective respondents over short messaging service (SMS) and IDIs were conducted only after receiving an affirmative SMS response from the participant. A set of instructions were sent before the conduction of actual IDI, including a request to make themselves available for at least $45 \mathrm{~min}$, minimize the disturbing factors while participating and sitting in a quiet place preferably alone for the audio IDI. These measures ensured successful conduction of IDIs and better interaction between the interviewer and the respondent.

In our study 69 eligible respondents were approached for participation and among them $13.04 \%$ (9/69) terminated the IDI before completion. The reasons cited by them were: inability to respond to male researchers $(n=2)$, inability to respond to interview questions alone (n $=2$, lacked time $(n=2)$ or experienced fatigue over long IDI $(n=3)$. After excluding them, 60 participants completed the IDI. The interviews were conducted using a pre-tested IDI guide (Appendix 1), in local language (Hindi) and lasted for 40-45 min. Researchers kept a research diary in which they recorded their daily reflections and analytical notes. In compliance with the principles of qualitative research, IDIs continued till saturation was achieved. ${ }^{17}$

\subsection{Data management and analysis}

In this study, we followed step-wise framework analysis. ${ }^{18}$ The steps were (i) transcribing audio-recorded IDIs and research diaries (ii) familiarizing with interviews (iii) coding using AtlasTi software version 8.0 (iv) developing a working analytical frame-work (v) applying that analytical framework (vi) charting the data into framework matrix and finally (vii) interpretation of qualitative data. ${ }^{18}$ Data analysis was done by the two lead researchers (TR and SA) who were not involved in data collection. The themes and their interpretations were later shared with four co-researchers (RK, MP, GS, VKV) who were directly involved in data collection to ensure that these were culturally-appropriate and represented the perceptions and behavior of the respondents. Conventional content analysis, in which categories are derived from data at the time of data analysis, was used. ${ }^{19,20}$ COREQ Checklist is being used to report this qualitative research. ${ }^{21}$ All audio-recorded IDIs were anonymized, given a unique identification number and were accessible only to the study investigators.

The standard terminology used in this manuscript to represent the frequency of responses against each code is as follows: All or almost all: 90-100\%; Most: 60-89\%; Some: $30-59 \%$ and Few: $\leq 29 \%$.

\section{Results}

From July-September 2020, 60 eligible participants completed the IDIs, of which $36.7 \%(22 / 60)$ were females. Socio-demographic characteristics of the respondents is given in Table 1 .

\subsection{Impact of COVID-19}

Almost all the respondents perceived that COVID-19 has impacted them either economically, socially or personally. Most respondents opined that they faced financial losses due to the pandemic. Certain types of businesses/shops like medical store, private hospital, clinics and grocery store were perceived to be facing fewer financial hardships compared to others (Table 2, Narrative 1 and 2).

At the personal level, most respondents felt that education of their children were compromised because of the pandemic as they do not 
Table 1

Socio-demographic characteristics of the respondents $(n=60)$ from the four participating districts.

\begin{tabular}{|c|c|c|c|c|c|}
\hline District & Lucknow & Etawah & Patna & Darbhanga & Total \\
\hline $\begin{array}{l}\text { Socio-demographic } \\
\text { characteristics }\end{array}$ & $\mathrm{n}=15$ & $\mathrm{n}=15$ & $\begin{array}{l}\mathrm{n}= \\
15\end{array}$ & $\mathrm{n}=15$ & $\begin{array}{l}\mathrm{n}=60 \\
\mathrm{~N}(\%)\end{array}$ \\
\hline \multicolumn{6}{|l|}{ Age (Years) } \\
\hline $21-30$ & 9 & 5 & 9 & 8 & $\begin{array}{l}31 \\
(51.67)\end{array}$ \\
\hline $31-40$ & 4 & 9 & 5 & 4 & $\begin{array}{l}22 \\
(36.67)\end{array}$ \\
\hline $41-50$ & 2 & 1 & 0 & 2 & $\begin{array}{l}05 \\
(08.33)\end{array}$ \\
\hline $51-60$ & 0 & 0 & 1 & 1 & $\begin{array}{l}02 \\
(03.33)\end{array}$ \\
\hline \multicolumn{6}{|l|}{ Gender } \\
\hline Female & 7 & 6 & 3 & 6 & $\begin{array}{l}22 \\
(36.67)\end{array}$ \\
\hline Male & 8 & 9 & 12 & 9 & $\begin{array}{l}38 \\
(63.33)\end{array}$ \\
\hline \multicolumn{6}{|c|}{ Respondents Education } \\
\hline Below Primary & 2 & 2 & 4 & 8 & $\begin{array}{l}16 \\
(26.67)\end{array}$ \\
\hline Above Primary & 13 & 13 & 11 & 7 & $\begin{array}{l}44 \\
(73.33)\end{array}$ \\
\hline \multicolumn{6}{|c|}{ Occupation Female Respondents $(n=22)$} \\
\hline Home maker & 5 & 5 & 3 & 6 & $\begin{array}{l}19 \\
(86.36)\end{array}$ \\
\hline Salaried Job & 2 & 1 & 0 & 0 & $\begin{array}{l}03 \\
(13.63)\end{array}$ \\
\hline \multicolumn{6}{|c|}{ Occupation of the male respondents $(n=38)$} \\
\hline Unemployed & 0 & 0 & 3 & 0 & $\begin{array}{l}03 \\
(7.89)\end{array}$ \\
\hline Salaried Job & 2 & 2 & 6 & 3 & $\begin{array}{l}13 \\
(34.21)\end{array}$ \\
\hline Daily wage laborer & 2 & 1 & 1 & 0 & $\begin{array}{l}04 \\
(10.53)\end{array}$ \\
\hline Farming & 0 & 3 & 0 & 4 & $\begin{array}{l}07 \\
(18.42)\end{array}$ \\
\hline Business & 4 & 3 & 2 & 2 & $\begin{array}{l}11 \\
(28.95)\end{array}$ \\
\hline \multicolumn{6}{|l|}{ Place of residence } \\
\hline Rural & 4 & 12 & 7 & 15 & $\begin{array}{l}38 \\
(63.3)\end{array}$ \\
\hline Urban & 11 & 3 & 8 & 0 & $\begin{array}{l}22 \\
(36.67)\end{array}$ \\
\hline \multicolumn{6}{|l|}{ Family Type } \\
\hline Joint & 10 & 13 & 12 & 9 & $\begin{array}{l}44 \\
(73.33)\end{array}$ \\
\hline Nuclear & 5 & 2 & 3 & 6 & $\begin{array}{l}16 \\
(26.67)\end{array}$ \\
\hline \multicolumn{6}{|l|}{ House type } \\
\hline Mud & 2 & 0 & 2 & 1 & $5(8.33)$ \\
\hline Bricks & 12 & 7 & 11 & 8 & $\begin{array}{l}38 \\
(63.33)\end{array}$ \\
\hline Combined & 1 & 8 & 2 & 6 & $\begin{array}{l}17 \\
(28.33)\end{array}$ \\
\hline
\end{tabular}

have the electrical gadgets (mobile/computer/laptops) or the internet connectivity. Few expressed that health-care for routine illnesses were being ignored due to fear/anxiety of visiting hospitals/clinics due to the pandemic. Few respondents shared loss of quality time with family due to posting in health/law/defense sector. This created mental stress and caused loss of quality time with the family (Table 2, Narrative 3).

At the social level, people felt that they were not able to meet their relatives and friends in social gatherings as frequently as they used to do in pre-COVID times. They added that restrictions on social gatherings/ large family functions caused mental stress and added to their financial woes caused by cancellation of pre-planned social events (Table 2, Narrative 4).
Table 2

Narratives from in-depth interviews.

Impact of COVID-19

Narrative 1

"I suffered huge losses because of corona. I took loan of Rupees 5000 for my fox-nuts farming but the entire crop got wasted due to corona and its restrictions. The harvested crop could not be sent for selling outside my district due to lockdown restrictions and it perished completely, causing huge losses" (Male, below primary educated, Darbhanga)

Narrative 2

"We have not suffered that much due to corona as others in my society. My husband has a medical store that was opened even during lockdown" (female, above primary educated, Lucknow)

Narrative 3

"Because of corona, we do not visit hospitals even for routine illnesses. My father has diabetes but we avoid hospitals these days as these places are more dangerous than even normal markets" (male, above primary educated, Etawah)

Narrative 4

"Because of corona, we are not able to meet our relatives. My cousin's marriage was scheduled in June this year (2020) but even that got cancelled. The money for booking of marriage hall was not returned causing financial loss. Now, the marriage has been postponed indefinitely for next year" (male, above primary educated, Etawah)

Self-reported rationale for poor compliance of PMs

Narrative 5

"People who are educated exercise safety. Those who are uneducated do not follow. People have no fear of this disease. It is deeply engrained in their mind that I will not get corona" (Female, above primary educated, Darbhanga)

Narrative 6

"The biggest problem in our country is poverty and illiteracy. Sixty percent people are illiterate. These people lack awareness about the disease" (Male, above primary educated, Etawah)

Narrative 7

"I do not know anybody who had corona. Those who have cough-cold and do not take precautions, they are probably spreading the disease" (Male, above primary educated, Darbhanga)

Narrative 8

"There are certain people who have learnt to live with this disease. They think nothing will happen to them. People have stopped fearing corona" (Male, above primary educated, Darbhanga)

Narrative 9

"People think they are safe. Nothing will happen to them, even if it happens to others" (female, below primary educated, Patna)

Narrative 10

"Those people who are not wearing mask must be thinking that they will face whatever (negative) befalls them. Moreover, some solution for this disease is bound to come up with time" (Female, above primary educated, Lucknow)

Narrative 11

"Everybody is aware of the disease, the only thing is that they are careless, they are not paying heed to it. They know that if 100 people fall ill with it, 95 will recover and only 5 will die due to it. Thus, they do not fear it" (Male, above primary educated, Lucknow) Narrative 12

"The only point is that many people do not understand that it is a serious disease. They think this disease is merely a rumor or a social hype. Even when they get sick, they try to hide the disease, thinking they have to stay at home for 14 days or the government will come and seal their house. The disease is spreading more because people are hiding the disease, although getting tested is always good" (Male, below primary educated, Etawah)

Narrative 13

"People do not follow rules; it depends on how they think about the disease. Personally, I believe that safety must be exercised at all levels. When people have fever, they do not get tested for the fear of being discriminated. Such people also do not follow social distancing to hide it" (Female, below primary educated, Patna)

Narrative 14

"It (COVID-19) is spreading more rapidly in cities. This disease is not that much (prevalent) in villages. In the cities, people are not being cautious, therefore it is spreading rapidly" (female, below primary educated, Lucknow)

Narrative 15

"There is a common belief that this disease is an illusion spread by a neighboring country Thus it has less impact on us" (female, below primary educated, Darbhanga)

Narrative 16

"Everything was ok till the government was strict. Now the system has left us. There is no strictness, thus the people are also overlooking precautions, although most people know that social distancing must be maintained, but still do not follow it" (male, above primary educated, Lucknow)

Rationale for not complying/poorly complying to wear face-masks Narrative 17 
Table 2 (continued)

Impact of COVID-19

"People say that they have difficulty breathing, rashes, and other problems. People are not developing wearing mask as a habit, instead they remove mask as soon as they reach a safe place" (Male, above primary educated, Lucknow)

Narrative 18

"There are some people who say they have problems wearing mask, like pain around ears and mouth due to hard tying string of mask. There are others who keep mask in their pocket but do not wear it" (Male, below primary educated, Lucknow) Narrative 19

"Those who do not wear face mask, it's their wish. These people do not consider it (COVID19) as a dangerous disease" (Male, above primary educated, Etawah) Narrative 20

"People do not follow because of carelessness. They think it is a joke. They will understand it in a hard way, when everybody will get sick" (Male, below primary educated, Darbhanga) Narrative 21

"If we wear mask, people rebuke by saying 'is corona going to catch only you'? Keep your mask with you' These people have made a mockery of this act. What can we do, we just can ensure our own safety by wearing it but we cannot argue others" (Male, above primary educated, Patna)

Narrative 22

"Most of the people in our society do not wear mask. They are not aware of the problem it can cause. People start wearing mask as soon as someone in the family is found corona positive" (Male, above primary educated, Lucknow)

Narrative 23

"This is not a disease; therefore, people are not wearing mask. What benefit can we have from wearing mask? We don't have any disease, why should we wear mask?" (Male, above primary educated, Etawah)

Narrative 24

"At the initial phase of the disease, the government made us aware. At that time, the administration used to deal strictly with people who did not wear mask. Now even people from administration are not wearing mask" (Male, below primary educated, Patna)

Narrative 25

"People think what difference they will make to the society by wearing a mask. Probably, they are tired of wearing it. All think that the government is politicizing the whole issue. I wear a mask because if I am safe, my family will be safe" (Male, above primary educated, Etawah)

Rationale for non-complying/poorly complying with social distancing (SD) Narrative 26

"In the marketplace, everybody is in a hurry to buy groceries. If a person follows a distance of 1-2 $\mathrm{m}$ and stands in a queue, others will think $s$ /he is a fool and will not wait for their turn, but disrupt the queue" (Male, below primary educated, Darbhanga)

Narrative 27

"The administration has to ensure social distancing. Unless and until the administration intervenes and enforces strict rules, people will not follow social distancing. In absence of any strictness by the administration, people will do what they feel like doing" (Male, above primary educated, Patna)

Narrative 28

"The people in village do not follow what is advised by the government. They follow social distancing only if they have a corona patient in the family. Else they say that we don't have this disease in our family, so why should we maintain social distancing? We are not sick" (Female, above primary educated, Etawah)

Narrative 29

"Till when are we going to follow these rules? We have to earn and think about our bread and butter. If we think more on this, we will starve. The only thing is that people must follow social distancing" (Male, above primary educated, Darbhanga)

Narrative 30

"Probably people think that since everything has been opened by the governments-hotels, markets and gatherings, now nothing is going to happen to them, the phase has passed" (Female, below primary educated, Lucknow)

\subsection{Self-reported rationale for poor compliance of PMs}

Respondents were asked their perceptions related to rapid spread of COVID-19 in society. Few respondents from Darbhanga, Lucknow and Patna district completely denied the presence of COVID-19 in his/her society. They opined that "corona was widely prevalent in their neighbourhood locality few months back but is not there presently". These respondents probably used denial of COVID-19 as a coping mechanism to rationalize the severity of the situation.

Respondents who concurred that COVID-19 was widely prevalent in society gave a wide range of reasons for poor/non-compliance to PMs. Most termed such attitude of the society as "carelessness towards the disease". Very few respondents opined that COVID-19 is spreading rapidly as people are not following the government prescribed recommendation of home isolation and moving in an unrestricted manner.

In our study, education was perceived to be directly associated with greater compliance of PMs. Few respondents perceived that COVID-19 is more common among less-educated compared to more-educated population. In their opinion, higher education was directly linked to improved compliance towards COVID-19 PMs (Table 2, Narrative 5 and $6)$.

Perceived severity of disease played a key role in shaping attitude and practices related to adherence of PMs. These people believed that COVID-19 often had less severe outcome and is thus less fatal. Some respondents perceived that COVID-19 is just a "mismanaged cold; for which treatment was not taken timely, thus making it turn severe". Often people base their judgments of an activity not only on what they think about it but also on how they feel about it. ${ }^{22}$ The lack of direct experience with the disease also attenuated this belief and made them under-estimate the risk due to it. Many perceived that since nobody in their immediate relation or social contact had fallen sick due to this disease, their susceptibility to get the disease is less (Table 2, Narrative 7).

Some respondents perceived themselves to be less susceptible to COVID-19 compared to others. They believed that all others excluding them were at the personal risk of contracting the disease. The findings reflect 'optimistic bias' (a type of cognitive bias) among the respondents that bad things are less likely to befall on themselves than others and can undermine the individuals' motivation to take precautions ${ }^{23}$ (Table 2, Narratives 8, 9 and 10). Respondents further believed that "even if they somehow get the disease, they will recover soon" as the recovery rate from COVID-19 in India is higher compared to other countries (Table 2, Narrative 11).

Social stigma associated with the disease caused many to hide the contagion and spread it rapidly. Respondents shared that many people in society "hide" the disease due to fear of discrimination that was common for COVID-19 positive patients. They shared that once a person is identified as COVID-19 positive, there are prominent restrictions like ambulance for taking the patient, barricading outside the patients' house to restrict family movement, and home isolation for 14 days. All these amplify the stigma and caused many to hide the disease and not take timely treatment, contributing it to spread further (Table 2, Narratives 12 and 13).

Respondents opined that COVID-19 is spreading dis-proportionally across rural-urban landscape. Some respondents from Patna and Lucknow were of the opinion that the disease is spreading rapidly in urban areas compared to rural. The reasons cited by them were high population density (people/land area) in urban, more intra district mobility of urban population and presence of urban slums. Respondents from rural sites (Etawah and Darbhanga) also believed that high crowding (people/ interior space area) in urban areas also amplified the risk (Table 2, Narrative 14).

Respondents felt strongly that the government is exercising laxity in implementation of COVID-19 PMs. Few respondents from Darbhanga and Etawah were of the opinion that COVID-19 has "political motive" and "it is a measure by the government to distract its citizens from more pressing questions like inflation, poverty, unemployment'. Few respondents were of the opinion that the disease was a "foreign virus" and is originally from a neighboring country and thus "weak here" and consequently less severe for us (Table 2, Narratives 15 and 16).

\subsection{Rationale for not complying/poorly complying to wear face-masks}

Respondents were asked reasons for non-compliance/poorcompliance to wearing face-masks. Respondents cited personal discomfort like "difficulty in breathing"; "insufficient oxygen intake", "feeling hot", "sweating" and "having rashes" etc. For flouting the recommendation. Few were shared beliefs like "more carbon-dioxide intake than oxygen intake, thus health risks" on wearing face-mask 
(Table 2, Narratives 17 and 18).

Another reason, commonly cited by the respondents was related to the perceived severity of the disease. Some respondents opined that people who are "careless", "do not fear corona" and believe that "good recovery rate makes people more relaxed" often do not wear face-mask (Table 2, Narratives 19 and 20).

Social pressure seemed to play a major role in making the society compliant towards wearing face-masks. Some respondents from Darbhanga and Etawah opined that wearing mask made them feel "socially strange" when rest of the society were not wearing it. They also feared facing discrimination, mockery and being rebuked if they went against the social norm of not wearing face-mask, widely prevalent in their society (Table 2, Narrative 21).

Some respondents believed that by following this PM will not reduce their susceptibility to or severity of illness and that this act of wearing face-mask needs to be followed only if somebody in the family was COVID-19 positive. These respondents concurred that "only the sick wear masks". Respondents also perceived their risk to catch COVID-19 was higher when someone in their family has already been diagnosed with this disease (Table 2, Narrative 22 and 23).

The GoI imposed certain penalties for not wearing face-masks. ${ }^{6}$ However, many respondents opined that there has been a gradual administrative laxity in the implementation of PMs as the pandemic progressed overtime and this has instigated many in the society to violate wearing face-masks at public places. Risk of getting rebuked also discouraged many respondents not to "interfere when others were not wearing it." They opined that in such situations, strict implementation measures by the government may be useful (Table 2, Narratives 24 and 25).

\subsection{Rationale for non-complying/poorly complying with social distancing} (SD)

Respondents were asked their views on whether SD was being followed in their society. All respondents unanimously reported that SD was not being followed as per the government recommendation, in most public areas. The reason most commonly cited by majority of respondents was laxity on part of government to implement SD with a heavy hand. They perceived that there are only limited penalties ${ }^{6}$ that are not rigorously implemented by the government at present, thus making people to flout it easily. High population density was also cited as an important reason for violating SD as due to huge crowds and less geographic space, it was practically impossible to practice $\mathrm{SD}$, even if recommended by the government (Table 2, Narrative 26).

Few respondents again cited that some people in society do not fear severe outcome from this disease, making them "careless" towards it. Other respondents stated that the disease has stretched beyond months, making people perceive the disease to be less serious. (Table 2, Narratives 27 and 28).

In our study, respondents believed that the benefits of earning/daily living costs (perceived benefits) outweigh the perceived risk of getting the disease. SD was outweighed by the perceived benefits of day-to-day living activities. This can be explained by the 'perceived benefit' construct of $\mathrm{HBM}^{11}$ (Table 2, Narrative 29). It also appeared that poor compliance to SD was not always a result of rational, conscious decision-making, but also a part of affective/emotional response attached with it. Perceived susceptibility to illness was lessened due to prolonged period through which the pandemic has lasted (Table 2, Narrative 30).

\section{Discussion}

Change in behavior of general public is crucial to preventing the transmission of COVID-19. ${ }^{9,24}$ Because societal behavior change is the key to curbing this pandemic, there is a pertinent need to provide scientific evidence that helps improve individuals' behavioral compliance to PMs. Currently there is a dearth of literature on this issue. ${ }^{24}$ To our knowledge, this is the first study from North India that explores the perceptions and practices of COVID-19 related PMs using qualitative inquiry of general population. Our qualitative insights are valuable not only to mitigate the spread of ongoing pandemic, but will also serve to inform the policy-makers to devise behavior-change programs that target specific preventive behaviors that are usually not followed for COVID-19.

In our study, there were multiple reasons for non-compliance to PMs in our population. First, the perception of risk towards COVID-19 was low in our population. Most people did not consider COVID-19 as a 'threat', citing reasons like low mortality, high recovery rate or absence of negative consequence due to COVID-19 in immediate family/relation/neigbour. A systematic review found that perceived susceptibility to and perceived severity of diseases are important predictors of compliant behavior. ${ }^{9}$ There is also evidence that an increased trust in government authorities is also positively associated with compliance. ${ }^{9}$ In our study, the respondents informed that administrative authorities themselves do not follow the recommended PMs. This provided cue to them to not adhere to the same as well.

The health-related behavior of our population can be explained by the behavioral constructs of the Health Belief Model. ${ }^{11-13}$ In our study, rural respondents perceived themselves to be less susceptible to COVID-19 as the disease was more prevalent among "the educated" or "the urban". This belief adversely impacted their intent to follow PMs for COVID-19. In addition to low perceived susceptibility, many respondents believed the disease to be less serious in nature, owing to high recovery rate or low fatality rate. This belief further lowered their 'perceived severity' of illness. Our respondents were unclear of the fact if they followed the recommended PMs, it would reduce the susceptibility or severity of COVID-19 or lead to other positive outcomes (perceived benefits) for them. The negative attributes related to following a particular social action (perceived barriers) were weighed highly by our respondents. Some of these negative attributes were personal discomfort of using face mask, inconvenience in following social distancing and feeling "socially strange" adding to social pressures of not following "because others were not doing it". In our study, social norms shaped collective behavior for complying/not complying to PMs. Many respondents shaped their thoughts because of 'empirical expectations' (what other people do) and also due to 'normative expectations' (what other people think we should do). ${ }^{25,26}$ Also, they considered complying with PMs as only a government-enforced measure and could not understand that it was for their own self-good.

Consistent with our study findings, inappropriate use of face mask during this pandemic has been reported by another study as well. ${ }^{27}$ We also report that SD was not much followed PMs at certain locations and in certain situations. Other literature also reports that adherence to SD faces strong practical, motivational and social barriers. ${ }^{28}$ Besides, it adds to considerable costs on people and society that are borne disproportionately by people who are already disadvantaged. ${ }^{28}$ Moreover, SD measures may be challenging to sustain due to financial pressures on family and lack of trust in government. These social and cultural paradigms must be kept in focus when recommending PMs and our study provides critical evidence in this context.

It has long been established by behavioral scientists that general public is more motivated to comply with and adapt PMs, if they understand the necessity and rationale behind the recommended actions. In a novel pandemic situation like COVID-19, lack of clear communication can lead to uncertainty and panic among the citizens. ${ }^{29}$ Therefore, our aim must be to design communications that do not 'persuade' people to a particular decision, instead make them understand what is known and let them decide on the basis of that evidence. ${ }^{29}$ In addition, it is also important to be clear about motivations, present data fully and clearly, and share sources. ${ }^{29}$ Moreover, 'one size fits all' approach may not contribute to effective containment of this pandemic. Our study reports rural-urban and educated-uneducated divide in compliance to PMs; which is consistent with findings of another knowledge, attitude 
and behavior survey on COVID-19 related PMs. ${ }^{30}$ To bridge this divide, customized plans tailored to local community's needs are urgently required.

\subsection{Study limitations}

One of the limitations of the study was conducting voice-only/audio telephonic IDIs. In this ongoing COVID-19 pandemic, video interviewing is more preferred than voice-only or in-person interviewing ${ }^{16}$ probably because video-interviewing is almost like in-person interviewing and it is easier to catch the non-verbal cues. ${ }^{31}$ However, our study was conducted in resource-constrained settings of India. In these states, use of smart-phones is not widely prevalent and only few respondents had a smart-phone to support video-conferencing with an active internet data-pack. Therefore, researchers had to resort to audio-interviewing instead of video-interviewing. Moreover, it has been reported that the difference of in-person over telephone interviewing is not substantial in terms of interview length, subjective interviewer ratings and substantive coding. ${ }^{31}$ Another limitation of our study is conduction in only four districts of North India. Our findings are thus unlikely to represent the entire country. However, these districts have common socio-cultural characteristics with other districts of North India. ${ }^{14,15}$ These make our findings relevant to other parts of North India as well.

\section{Conclusion}

As we continue to face unprecedented times, an understanding of perceptions and behaviours of the general public will inform the development of risk communication interventions. These are pertinent not only to control the spread of COVID-19 infection but also mitigate the harm done by it. Our study found poor community compliance to COVID-19 response. To improve adherence to recommended behaviors, the community must be involved and effectively engaged through early discussions and negotiations in devising appropriate health promotion and risk communication strategies. ${ }^{32,33}$ Accurate and well-developed culturally-sensitive health communication can facilitate how societies handle uncertainty and fear associated with the pandemic and promote and accomplish adherence to the necessary behavior change. ${ }^{32-34}$ It can also encourage informed decision-making and promote positive behavior change $\mathrm{e}^{34-36}$ which is much required for this pandemic.

\section{Data availability}

The corresponding author has full control of all primary raw data (in Hindi) and the data may be made available on request.

\section{Funding}

This research received no specific grant from any funding agency in the public, commercial, or not-for-profit sectors.

\section{CRediT authorship contribution statement}

Tuhina Rastogi: Conceptualization, Data curation, Formal analysis, Investigation, Methodology, Project administration, Supervision, Validation, Visualization, Writing - original draft, Writing - review \& editing. Shally Awasthi: Conceptualization, Formal analysis, Methodology, Supervision, Validation, Writing - original draft, Writing - review \& editing. Ranjan Khare: Investigation, Data curation, Formal analysis. Mahesh Prasad: Investigation, Data curation, Formal analysis. Gulshan Sami: Investigation, Data curation, Formal analysis. Vijay Kumar Verma: Investigation, Data curation, Formal analysis.

\section{Declaration of competing interest}

The authors declare that they have no competing interests.

\section{Acknowledgements}

Authors are highly grateful to the participants for their time and valuable contribution in this research. We are also acknowledging the conducive environment provided by the administration of King George's Medical University, Lucknow that facilitated implementation of this study in pandemic times.

\section{Appendix A. Supplementary data}

Supplementary data to this article can be found online at https://doi. org/10.1016/j.cegh.2021.100927.

\section{References}

1 Lu H, Stratton CW, Tang YW. Outbreak of pneumonia of unknown etiology in wuhan China: the mystery and the miracle. J Med Virol. 2020;92(4):401-402.

2 n.d. Coronavirus disease (COVID-19) - World Health Organization. Available:, $23^{\text {rd }}$ November, 2020 https://www.who.int/emergencies/diseases/novel-coronavir us-2019

3 Li Q, Guan X, Wu P, et al. Early transmission dynamics in Wuhan, China, of novel coronavirus-infected pneumonia. N Engl J Med. 2020;382:1199-1207. https://doi. org/10.1056/NEJMoa2001316.

4 World Health Organization. Critical Preparedness, Readiness and Response Actions for COVID-19: Interim Guidance, 4 November 2020. World Health Organization; 2020.

5 Ferguson NM, Laydon D, Nedjati-Gilani G, et al. Impact of Non-pharmaceutical Interventions (NPIs) to Reduce COVID-19 Mortality and Healthcare Demand. Imperial. Ac.Uk; 2020. https://doi.org/10.25561/77482. March.

6 Government of India Ministry of Health \& Family Welfare. COVID-19 India. Available:, $23^{\text {rd }}$ January , 2021 https://www.mohfw.gov.in/.

7 Adams J. Recommendation regarding the use of cloth face coverings, especially in areas of significant community-based transmission. Available:, $23^{\text {rd }}$ November, 2020 https://www.cdc.gov/coronavirus/2019-ncov/prevent-getting-sick/cloth-face-cove r.html; 2020.

8 World Health Organization. Coronavirus disease (COVID-19) advice for the public. Coronavirus disease (COVID-19) advice for the public: when and how to use masks. Available, $23^{\text {rd }}$ November, 2020 https://www.who.int/emergencies/diseases/n ovel-coronavirus-2019/advice-for-public/when-and-how-to-use-masks.

9 Bish A, Michie S. Demographic and attitudinal determinants of protective behaviours during a pandemic: a review. Br J Health Psychol. 2010 Nov;15(4):797-824.

10 Lancet T. India under COVID-19 lockdown. Lancet (London, England). 2020 Apr 25; 395(10233):1315.

11 Janz N, Champion V, Stecher V. The Health Belief Model in Theory at a Glance: A Guide for Health Promotion Practice (NIH 95-3896. Bethesda, MD: National Institute of Health, National Cancer Institute; 1995.

12 Green EC, Murphy EM, Gryboski K. The health belief model. The Wiley Encyclopedia of Health Psychology. 2020 Sep 2:211-214.

13 Rosenstock IM. Historical origins of the health belief model. Health Educ Monogr. 1974 Dec;2(4):328-335.

14 [Internet]. Annual Health Survey (AHS) Factsheet 2012-13 Uttar Pradesh. New Delhi: Office of Registrar General \& Census Commissioner, Ministry of Home Affairs, Government of India; 2010-2011. Available from:http://www.censusindia.gov.in/vi tal_statistics/AHSBulletins/AHS_Factsheets_2012-13/FACTSHEET-UTTAR_PRADE SH.pdf, $5^{\text {th }}$ October, 2020.

15 [Internet]. Annual Health Survey (AHS) Factsheet 2012-13 Bihar. New Delhi: Office of Registrar General \& Census Commissioner, Ministry of Home Affairs, Government of India; 2010-2011. Available:http://www.censusindia.gov.in/vital_statistics/AHS Bulletins/AHS_Factsheets_2012-13/FACTSHEET-Bihar.pdf, $5^{\text {th }}$ October, 2020.

16 Lobe B, Morgan D, Hoffman KA. Qualitative data collection in an era of social distancing. Int J Qual Methods. 2020 Jul 2;19, 1609406920937875.

17 Morse JM. The significance of saturation. Editorial. Available: https://journals.sagep ub.com/doi/pdf/10.1177/104973239500500201.

18 Gale NK, Heath G, Cameron E, Rashid S, Redwood S. Using the framework method for the analysis of qualitative data in multi-disciplinary health research. BMC Med Res Methodol. 2013 Dec;13(1):1-8.

19 Hsieh HF, Shannon SE. Three approaches to qualitative content analysis. Qual Health Res. 2005 Nov;15(9):1277-1288.

20 Glaser B, Strauss A. The Discovery of Grounded Theory: Strategies for Qualitative Research. New Brunswick: Aldine Transaction; 1999.

21 Tong A, Sainsbury P, Craig J. Consolidated criteria for reporting qualitative research (COREQ): a 32-item checklist for interviews and focus groups. Int J Qual Health Care. 2007 Dec 1;19(6):349-357.

22 Alhakami AS, Slovic P. A psychological study of the inverse relationship between perceived risk and perceived benefit. Risk Anal. 1994 Dec;14(6):1085-1096.

23 Park T, Ju I, Ohs JE, Hinsley A. Optimistic bias and preventive behavioral engagement in the context of COVID-19. Res Soc Adm Pharm. 2021 Jan 1;17(1): 1859-1866.

24 West R, Michie S, Rubin GJ, Amlôt R. Applying principles of behaviour change to reduce SARS-CoV-2 transmission. Nat Hum Behav. 2020 May 6:1-9.

25 Bicchieri C. The Grammar of Society: The Nature and Dynamics of Social Norms. Newyork NY: Cambridge University Press; 2006. 
26 Abrams D, Wetherell M, Cochrane S, Hogg MA, Turner JC. Knowing what to think by knowing who you are: self-categorization and the nature of norm formation, conformity and group polarization. Br J Soc Psychol. 1990 Jun;29(2):97-119.

27 Feng S, et al. Rational use of face masks in the COVID-19 pandemic. S2213-2600 Lancet Respir Med. 2020;(20), 30134-X.

28 Baum NM, Jacobson PD, Goold SD. "Listen to the people": public deliberation about social distancing measures in a pandemic. Am J Bioeth. 2009 Nov 4;9(11):4-14.

29 Cowper A. Covid-19: are we getting the communications right? BMJ. 2020 Mar 6: 368.

30 Babalola S, Krenn S, Rimal R, et al. KAP COVID Dashboard.Johns Hopkins Center for Communication Programs, Massachusetts Institute of Technology; 2021. Global Outbreak Alert and Response Network, Facebook Data for Good. Published September 2020. Data retrieved January https://ccp.jhu.edu/kap-covid/.
31 Johnson DR, Scheitle CP, Ecklund EH. Beyond the in-person interview? How interview quality varies across in-person, telephone, and Skype interviews. Soc Sci Comput Rev. 2019 Dec 11, 0894439319893612.

32 Sumo J, George G, Weah V, et al. Risk communication during disease outbreak response in post-Ebola Liberia: experiences in Sinoe and Grand Kru counties. Pan Afr Med J. 2019;33(suppl 2).

33 Finset A, Bosworth H, Butow P, et al. Effective health communication-a key factor in fighting the COVID-19 pandemic. Patient Educ Counsel. 2020 May;103(5):873.

34 Gilmore B, Ndejjo R, Tchetchia A, et al. Community engagement for COVID-19 prevention and control: a rapid evidence synthesis. BMJ Global Health. 2020 Oct 1;5 (10), e003188.

35 Blastland M, Freeman AL, van der Linden S, Marteau TM, Spiegelhalter D. Five Rules for Evidence Communication. 2020.

36 Taylor S. The Psychology of Pandemics: Preparing for the Next Global Outbreak of Infectious Disease. Cambridge Scholars Publishing; 2019 Oct 7. 